\title{
An Analysis of Multi-modal Reading Class for Elementary English Language Learners under Immersive Language Environment---Take American Classes as an Example
}

\author{
Xiangyi Liu ${ }^{1, \dagger}, \mathrm{Pu} \mathrm{Meng}^{2, \dagger}$, Yuxing $\mathrm{Xie}^{3, \dagger}$, Hanyun $\mathrm{Yu}^{4, *, \dagger}$ \\ ${ }^{1}$ College of Education, University of Florida, Gainesville, FL, US. \\ ${ }^{2}$ School of Western Languages, Harbin Normal University, Harbin, Hei Longjiang, China \\ ${ }^{3}$ School of Information Engineering, Fuyang Normal University, Fuyang, Anhui, China \\ ${ }^{4}$ School of Foreign Languages, Beihang University, Beijing, Beijing, China \\ *Corresponding author. Email: 596945505@buaa.edu.cn \\ These authors contributed equally.
}

\begin{abstract}
Multi-modal teaching has become a hot research area of teaching innovation in recent years. The traditional reading teaching with the multi-modal teaching method has better effects. The problem is that whether multi-modal teaching will promote the effect of reading teaching, or what the extent of the effect is. The essay assumes that multi-modal teaching will promote the effect of reading teaching. The essay adopts qualitative methods and quantitative methods to compare the learning effect of reading classrooms that use multi-modal teaching and reading classes that do not use multi-modal teaching. The result is that the multi-modal method will promote the effect of reading teaching, and the effect is significant.
\end{abstract}

Keywords: multi-modal teaching, reading classes, elementary English Language Learners, American classes

\section{INTRODUCTION}

According to U.S. federal law, English Language Learners refers to students who have limited English proficiency. In the U.S., the percentage of public school students who are English Language Learners is on the rise in recent years. The National Center for Education Statistics (NCES) reported there were 5.0 million ELL students in the U.S. public school system in fall 2018, while there were 4.5 million in Fall 2010 [1]. Nevertheless, the increasing number of ELL students also faced increasing challenges. Blair et al. argued that countries such as the United Kingdom and the United States, still hold monoglossic language ideologies assuming that all students should follow the monolingual and mono-cultural norms [2]. When mainstream classrooms are dominated by the English language only, the emergent bi/multilingual is considered as lacking the knowledge of English. These ELLs are facing many challenges when they have to study and interact with others in an unfamiliar immersive language environment.

Various researches have addressed the issue from different aspects and different subjects. For example, Kress and Leeuwen stated that the 21st century is filled with mixed types of communication such as images, writing, layout, sound, gesture, speech [3]. Multimodality looks beyond language and examines these multiple types of communication and meaning-making. As the development of various forms of technology and media, Lotherington et al. mentioned that there has been increased professional interest and awareness in English language teaching methods based on multi-modal stance in recent years [4]. With the trend of various ways of communication, multi-modal learning has been proved as an efficient way to help students overcome challenges. Hafner suggested that multi-modal composition means activities that help learners to construct texts in multiple semiotic modes, including writing, image, and sound through digital tools [5]. 
Since the concept of multi-modality was introduced, many scholars have conducted researches on multimodal teaching. Bird \& Williams had demonstrated in their experiments that bimodal input could improve both native and non-native English speakers' recognition memory for spoken words and non-words compared to single modality input [6]. Furthermore, Kuo et al. analyzed the effects of a multi-modal presentation system on Turkish Elementary Students in English as a Second Language class, it showed there's a significant positive effect on students' English learning achievement and learning satisfaction [7]. Ntelioglou et al. also conducted a multilingual and multi-modal approach among ELLs from diverse cultural backgrounds in Toronto, Canada [8]. They found that students increased their literacy engagement, literacy investment, and learning by the stimulation of multiple texts and various ways of learning such as drama, creative writing, and digital tools. Through the previous relevant studies, it showed the multi-modal teaching methods are highly valued by researchers.

While efforts are been made for ELLs by researchers around the world, however, there are still some gaps in multi-modal teaching for teaching English Language Learners who come from diverse backgrounds to study abroad and live in a country that English is the domain language. For example, Harman and Shin found that digital multimedia resources are not available for all urban school teachers in the U.S [9]. Moreover, teachers usually face challenges not only from the limited budgets but also the lack of technical training and professional support. GáNdara, P. also advocated earlier that the California school district should give high priority professional development to teachers of English learners [10]. Those situations have been barriers to implementing a multi-modal literacy classroom. Also, Grapin \& Llosa pointed that the cognitively oriented and socially oriented perspectives on multi-modality with L2 learners in each context are still lacking [11]. We need more attention and efforts to support ELLs.

The purpose of this article is to analyze the difficulties faced by ELLs at elementary school in English language acquisition in an immersive language environment, to analyze the advantages of multi-modal reading classes over mono-modal reading classes, and to propose strategies for multi-modal teaching in ELA courses.

\section{ENGLISH LANGUAGE LEARNING AND READING CHALLENGES FOR ELEMENTARY ENGLISH LANGUAGE LEARNERS}

According to National Center for Education Statistic, "In Fall 2018, The percentage of public school students who were English Language Learners was 10.2 by average, ranged from 0.8 percent in West Virginia to
19.4 percent in California. It was 10.0 percent or more in 10 states." [1] In 2019, ELLs of 4th-grade students showed lower performance compared to Non-ELL students in Average National Assessment of Educational Progress (NAEP) reading scale scores. [12] The government has provided multiple language assistance programs to support English Language Learners to attain English proficiency. However, they are still facing many challenges when they have to use English as the school language to study and interact with others. Factors such as the lack of vocabulary, the complexity of the text, the connection between the content and the students...those are influencing students' engagement both in English Language Arts class and school life.

Reading in an unfamiliar language while you are still in the process of learning is quite challenging. Geva and Farnia stated that second language students usually show lower performance on English reading comprehension tasks compared to native English speakers [13]. Besides, Fillmore and Fillmore added that English learners and language minority students are experiencing problems that there is little understanding in our community of the role played by language in the process of attaining literacy [14]. Many challenges need to be noticed by the public.

Reading is a necessary social and cultural skill for people's survival and development in nowadays society. It is also one of the focuses of English literacy education. However, the current situation of English reading teaching urges us to deeply reflect on the problem. Kamps et al. stated that the current resources are not available to address both language and literacy instruction, especially considering the rapidly growing ELL population in larger cities in the U.S. [15]. In the traditional model, reading teaching mainly focuses on the vocabulary, the language in the text. But there are far more challenges that non-native English readers encounter in the classroom. This chapter mainly illustrates several issues rising in English language learning for elementary school's ELLs in the U.S.

\subsection{Reading Challenges for English Language Learners from Text}

The Common Core Standards had introduced a three-part model for measuring text complexity. [16] Qualitative measures refer to factors such as meaning or purpose, knowledge demands, and language clarity. Quantitative measures refer to factors such as word and sentence length and the frequency of unfamiliar words. Meanwhile, particular readers and tasks must also be considered. 


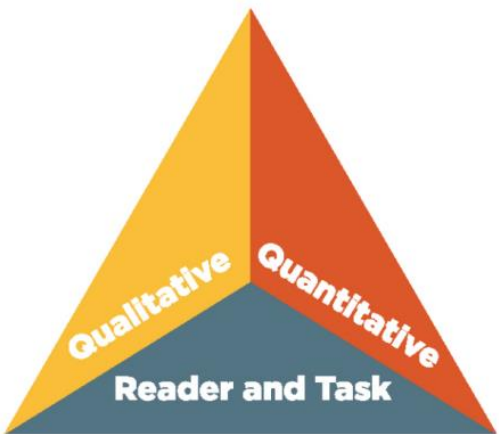

Figure 1 Model for Text Complexity, 2021 Common Core State Standards Initiative. [17]

English language learners may encounter more unfamiliar vocabularies in the text compared to native speakers. From the qualitative and quantitative aspects, the frequency of unfamiliar words will increase the complexity of text for ELLs. Amendum et al. added that when elementary students read complex texts, their fluency rate, decoding accuracy, and comprehension of the content will reduce [18]. As students' reading fluency and comprehension will be influenced by the complexity of the text, ELLs are facing more challenges from the text.

Also, Fillmore and Fillmore argued that the grammar used in the text is more formal than it in spoken language [14]. And some words common in texts are not being used frequently in daily conversations. Moreover, English language learners usually communicate in their first language at home. As a result, they may not be exposed in a home environment to practice the vocabulary, grammar, idioms, and figurative languages in academic texts. Their English reading experience and skills may only get from school, which is limited compared to native speakers.

\subsection{Reading Challenges for English Language Learners from Cultural Perspective}

Creighton had illustrated a phenomenon that minority students' culture is rarely reflected in the book they learned in schools [19]. As literacy is important in students' social, psychological, and cognitive development, it is hard for ELLs to find themselves through the book if it was not about their cultures. Jaeger also indicated that sociocultural context is a superior factor in a reader's English reading experiences [20]. Faigley et al. had addressed that cultural related barriers have been problems for Elementary ELLs to get to know the different connotations of their home language and English Language [21]. On the one hand, it affects people's way of thinking, behaviors, and values. On the other hand, it leads to the different cultural connotations in different languages. In the process of different language and cultural exchanges, due to the differences of cultural connotations in the language, the same words represent different meanings. For example, in Chinese, "appointment" usually indicates dates between people in a relationship. In English, "appointment" has a wider and more neural meaning. Therefore, Kress and Leeuwen argued that we should have an in-depth understanding of the cultural connotation of vocabulary [3]. Under the influence of different histories, geography, economy, and politics, different cultural forms were produced. It is a great challenge for young ELLs to break through the language barriers influenced by different cultural backgrounds. Ebe claimed that readers show more comprehension when reading the story identified as being more culturally relevant [22].

It is challenging to read without the relevant cultural background. Bunch et al. emphasized that literacy learning is a cultural and historical activity [23]. A lot of stories in ELA books are based on specific historical settings, with a combination of idioms and figurative languages. The challenges for second-language readers increase especially when unfamiliar content appears. Because they don't acquire related prior background knowledge about American culture. Moreover, they don't feel motivated if the content is not related to their own cultural experience. Drucker agreed that linguistic knowledge is not enough for reading comprehension [24]. She also suggested some picture books such as Red is a Dragon and Round is a moon cake, The Ugly Vegetables, and The Iguana Brothers. Those literature reflecting English Language Learners' personal experience will add their motivation for reading and reading comprehension. Overall, we need to have more cultural-related literacy for students, especially ELLs. It is an efficient solution for them to feel involved and motivated in English learning.

\subsection{Learning Environment Problems in English Language Learning}

English learning, like mother tongue learning, is inseparable from the language environment, and a good foreign language learning environment plays a significant and subtle role in promoting foreign language acquisition. In classroom teaching, the humanistic education concept and immersive learning can also improve the communicative activities in the classroom. Due to the characteristics of immersive teaching, there are more activities in immersive teaching classes, which brings challenges to teachers' classroom management.

In terms of classroom management, humanistic education believes that classroom management is realized by respecting people's subjectivity and value, not by command and coercion. Influenced by this idea, 
the American classroom has strong democratization. American classrooms pay attention to personalized development, advocate differentiated teaching, pay attention to the interaction between students, and give children a variety of forms of expression in the display and test of classroom learning effects. There are more activities. The school will carry out a series of games and activities to stimulate students' interest. These activities are multi-modal learning processes. For example, handicrafts and drama can enable students to participate in the class. Elementary education in the United States focuses on students. Encouraging education is popular in the United States. Students should be encouraged to continue to work hard regardless of their grades. This can be reflected in the classroom layout. Teachers will change the classroom layout according to students' age and teaching objectives to create a good learning environment for students. The American educational concept pays more attention to the cultivation of students' social ability, cognitive ability, and students' classroom participation. This is an immersive, multi-modal learning model. But this model of education also has drawbacks. In fact, there are still many American schools that use monomodal teaching.

The main problem is that not all American elementary education follows such an autonomous, immersive, multi-modal approach. This is also a problem to be studied and solved at present.

\section{ELA CLASSROOM TEACHING STRATEGIES IN ENGLISH LANGUAGE ENVIRONMENT}

In the U.S., ELLs are enrolled in the same classrooms as native speakers. Although they may receive support from English as a second language (ESL) classes, they stay in the regular classroom for most of the time. Teachers should make the necessary accommodations.

In the traditional elementary school reading teaching in the past, teachers in English Language Arts class mainly interact with the teaching content through two aspects: one is when transmitting the content in the textbook in their way, and the other is when teachers prepare lessons. This chapter mainly illustrates some classroom teaching strategies in the English language environment.

\subsection{Single -modal Classroom Teaching Strategy for Second Language Learners in English Language Environment}

As analyzed above, English language learners may encounter a variety of problems and don't perform as well as native students when learning in an unfamiliar immersive language environment. One of the important reasons is that teachers are not using the appropriate teaching method so that English language learners may have difficulty achieving comprehensive understanding through traditional single-modal teaching methods. Bowman-Perrott et al. said that ELLs represented a very heterogeneous group in terms of their native language proficiency, educational experiences, access to quality early childhood programs, and immigration experiences, but they often showed poor academic achievement, particularly in reading [25].

Taking classroom interaction as an example, some teachers would like to make students participate in class by asking questions. However, some English Language Learners may feel uncomfortable or embarrassed because asking questions is regarded as disrespectful in their countries. Afterward, these students may always be nervous during the lesson, listen poorly, or even lose interest in the lesson. Some teachers require students to read textbooks and extracurricular materials that they consider to be simple before class. Indeed, Students whose experience is not in the mainstream, therefore, will often need additional explanation and examples to draw the connection between new material and their existing knowledge bases. What's more, according to Zehler's example of textbooks, teachers always recognize that collecting materials in a variety of formats can enhance instruction and make students more engaged in the classroom [26]. Therefore, teachers will try to prepare pictures, diagrams, and photos along with the text to help students deepen their understanding and now most reading materials include pictures as an integral part of the book. Students react to the layout of the text first. For example, the general look of the text, the use of illustrations, and the font size. Attracting layout may generate students' interest and provide supports for readers. This single modal teaching method of combining text and pictures, which mainly uses children's visuals, has a positive effect on enhancing English Language Learners' interest in reading and helping them understand the text. However, when they study the textbooks with images, some of them may still be confused about some contents and don't dare to ask teachers or students due to their poor English. Both of these problems demonstrate the limitations of singlemodal teaching in the delivery process.

Some scholars have found the problems existing in the traditional teaching model and put forward the concept of multi-modal teaching constructively. For example, in Reading Multi-modal Texts: Perceptual, Structural and Ideological Perspectives, Serafini described the importance and value of multi-modal teaching [27]. Multi-modal teaching refers to using a variety of teaching methods to mobilize people's five senses to work together, including vision, hearing, touch, smell, and taste, to deepen impression and strengthen memory. The emergence of multi-modal teaching has brought many positive changes to the 
reading classroom in the immersive language environment.

\subsection{Classroom Teaching Reading Strategies for English Language Learners in English Language Environment}

The classroom teaching reading strategies of second language learners in an English language environment need to be multi-modal. Multi-modal teaching is beneficial to ELA reading classroom teaching.

Under the background of a developed network, the research on knowledge is no longer limited to textbooks, so the teachers have thought up various teaching methods to deliver the reading strategies to second language learners, and the interaction between teachers and teaching content is not only reflected in teachers' lesson preparation but also reflected in Teachers' creation of teaching content and design of teaching activities. One of the advantages of multi-modal teaching is that it can create a relatively real language environment. In the traditional elementary school English reading teaching, students are always influenced by cramming and insulated language teaching, and they rarely have the opportunity to practice the target language. Therefore, students lose interest in English and motivation to learn English. They often feel bored in class. In contrast, the combination of sound, image, and video with other modes can establish a relatively real language environment. At the same time, it can continuously stimulate students' different sensory organs. Therefore, under such vivid and interesting circumstances, their interest in learning English can be greatly enhanced. Multi-modal classroom activities not only create a lot of flexibility but also provide many students with opportunities to practice the language. In addition, the correct use of multi-modal teaching can create a relaxed and active classroom atmosphere, leading to a harmonious and even intimate relationship between teachers and students, which is conducive to the improvement of the teaching effect.

With the rapid development of information technology, the method of the Internet could not be ignored and provides a good platform for teachers to update teaching content online. Therefore, teachers can add more interesting and vivid content according to teaching needs. In most cases, Meyer et al. stated that the interaction between teachers and students can provide teachers with inspiration for innovative thinking, to make teaching materials more suitable for the needs of modern students, and the interaction between students and teaching content is more effective [28]. Therefore, in order to meet the needs of contemporary students, teachers must constantly fill in and update their professional knowledge and teaching literacy, which also requires teachers to explore new knowledge together with students, so that teachers can change from teachers to participants, supervisors, and helpers.

\section{IMMERSION SECOND LANGUAGE ACQUISITION AND READING TEACHING IN MULTI-MODAL CLASSROOM TEACHING PRACTICE}

According to Hassett and Curwood's research, the teacher divided the classroom into four modes, visual mode, auditory mode, tactile mode, and spatial mode [29]. To maximize its effect, it is necessary to consider its suitability.

Before class needs to do a survey of the learning situation and establish a learning goal. According to students' English basic situation, the teacher divided the article into some parts, so that students can consciously participate in the class. Secondly, the teacher needed an analysis of key points. For the reading class, the key point was to master the vocabulary and key phrase sentence patterns. However, students needed to make full use of multi-modal learning materials was difficult. In terms of the learning process, there were three parts, pre-reading, while-reading, and post-reading. The teacher demonstrated the multi-modal reading material based on these three processes, students consolidated knowledge through a series of ways to stimulate students' interest in reading and enhance students' memory. In this reading class, the main uses were visual mode and visualization. The teacher used these ways to interact with the text of the book so that students were no longer the audience, they can use these methods to help themselves to read more fluently, even they can ask some questions. After class, teachers can summarize and reflect on the process of teaching design in class, and make corresponding rectification measures.

The use of multi-modality in the teaching process increases the opportunities for teacher-student interaction and student-student interaction, and also gives students the chance to practice in the course of teaching assignments. learning tasks clear and complete can attract students' attention so that learning motivation to maintain a higher level so that the teaching activities smoothly. In traditional reading teaching, the content of the article is difficult to understand, which not only increases the time cost and difficulty for teachers in preparing lessons but also makes students tired and lose interest in text reading.

However, multi-modal learning improves these shortcomings. It is beneficial to improve students' reading interest and enthusiasm. Teachers can divide students into some groups to participate in the discussion. In this mode, teachers need to use various teaching methods. The combination of various teaching methods can not only enhance the reading instruction efficiency but also can make full use of the teaching resource. Teachers' multi-modal teaching has the role of 
leading and guidance. It can create an environment that students can communicate closely so that students can improve the practical use of language and communication skills. The traditional English teaching emphasizes words, grammar, exam education as the main training pattern, it lacks combination with the real environment, teachers also tend to ignore the real context. As a result, students can only read but not apply.

Ajayi introduced a new possibility that gives teachers and learners for design teaching and learning the English language.[30] Based on semiotics and Halliday's theory of systemic functional linguistics, he observed how teachers used multimodal teaching materials to teach English by class observations and notes. In the United States, including many places, textbooks are still the important way students are taught. Therefore, teachers need to understand that multimodal resources are at the heart of ELL material design and students' learning, and they need to find their accuracy and cultural representation when selecting textbooks. In the teaching process, English textbooks are organized by structures in which images become an important part of meaning formation and classroom learning and are crucial in how students express and communicate knowledge through multimodal textbooks. Teachers use images to contextualize teaching, creating a space for students to understand the meaning of textbook expression using their background. It can be shown that teachers can help students better understand textbooks and master knowledge through a multi-modal approach.

\section{CONCLUSION}

In multi-modal mode, it has significant advantages for students' second language acquisition. This learning process is a process of explore. It is not only the process of information input but also stresses students' consciousness of independent inquiry. In this mode, it reflects the practicability of English teaching and enables students to participate in and stimulate their interest. The study of multi-modal reading teaching can deepen the understanding of classroom teaching and learning, improve the quality of teaching, and make the originally boring reading classroom proceed in an orderly and efficient manner. At the same time, students' learning will be more interesting, making them like reading more and more. There are also some limitations. First, teachers' ideas are not modern enough. Second, Students participation is low. Thus, further study will continue to study and solve them.

\section{REFERENCES}

[1] COE - English Language Learners in Public Schools. (2021, May). National Center for Education Statistics. Retrieved October 23, 2021, from

https://nces.ed.gov/programs/coe/indicator/cgf

[2] Blair, A., Haneda, M., \& Bose, F. N. (2018). Reimagining English-Medium Instructional Settings as Sites of Multilingual and Multimodal Meaning Making. TESOL Quarterly, 52(3), 516539. https://doi.org/10.1002/tesq.449

[3] Kress, G., \& Leeuwen, T. V. (2001). Reading and writing with images: a review of four texts. Reading Images: The Grammar of Visual Design. Computers and Composition, 18(1), 85-87. https://doi.org/10.1016/s8755-4615(01)00042-1

[4] Lotherington, H., Tan, S., O'Halloran, K., Wignell, P. \& Schmitt, A. (2019). Analyzing the talking book Imagine a world: A multimodal approach to English language learning in a multilingual context. Text \& Talk, 39(6), 747-774. https://doi.org/10.1515/text-2019-0239

[5] Hafner, C. A. (2015). Remix Culture and English Language Teaching: The Expression of Learner Voice in Digital Multimodal Compositions. TESOL Quarterly, $\quad 49(3)$,

486-509. https://doi.org/10.1002/tesq.238

[6] Bird, S. A., \& Williams, J. N. (2002). The effect of bimodal input on implicit and explicit memory: An investigation into the benefits of within-language subtitling. Applied Psycholinguistics, 23(4), 509533. https://doi.org/10.1017/s0142716402004022

[7] Kuo, F. O., Yu, P. T., \& Hsiao, W. H. (2015). Develop and Evaluate the Effects of Multimodal Presentation System on Elementary Student Learning Effectiveness: Within Classroom English Learning Activity. Procedia - Social and Behavioral Sciences, 176, 227-235. https://doi.org/10.1016/j.sbspro.2015.01.465

[8] Ntelioglou, B. Y., Fannin, J., Montanera, M., \& Cummins, J. (2014). A multilingual and multimodal approach to literacy teaching and learning in urban education: a collaborative inquiry project in an inner city elementary school. Frontiers in Psychology, 5. https://doi.org/10.3389/fpsyg.2014.00533

[9] Harman, R., \& Shin, D. S. (2018). Multimodal and Community-Based Literacies. Advances in Early Childhood and K-12 Education, 217-238. https://doi.org/10.4018/978-1-5225-3955-1.ch011

[10] GáNdara, P. (2005). Listening to Teachers of English Language Learners: A Survey of California Teachers' Challenges, Experiences, and Professional Development Needs. University of California Linguistic Minority Research Institute. 
Retrieved October 13, 2021, from https://escholarship.org/uc/item/6430628z

[11] Grapin, S. E., \& Llosa, L. (2020). Toward an integrative framework for understanding multimodal L2 writing in the content areas. Journal of Second Language Writing, 47, 100711. https://doi.org/10.1016/j.jslw.2020.100711

[12] NAEP Nations Report Card - Interpreting NAEP Reading Results. (2020, October 20). National Center for Education Statistics. Retrieved October 23, 2021, from https://nces.ed.gov/nationsreportcard/reading/interp ret_results.aspx

[13] Geva, E., \& Farnia, F. (2011). Developmental changes in the nature of language proficiency and reading fluency paint a more complex view of reading comprehension in ELL and EL1. Reading and Writing, 25(8), 1819-1845. https://doi.org/10.1007/s11145-011-9333-8

[14] Fillmore, L. W., \& Fillmore, C. J. (2012). What Does Text Complexity Mean for English Learners and Language Minority Students? Stanford Graduate School of Education.

[15] Kamps, D., Abbott, M., Greenwood, C., ArreagaMayer, C., Wills, H., Longstaff, J., Culpepper, M., \& Walton, C. (2007). Use of Evidence-Based, Small-Group Reading Instruction for English Language Learners in Elementary Grades: Secondary-Tier Intervention. Learning Disability Quarterly, 30(3), 153-168. https://doi.org/10.2307/30035561

[16] Common Core State Standards Initiative. (2021). English Language Arts Standards » Standard 10: Range, Quality, \& Complexity » Measuring Text Complexity: Three Factors | Common Core State Standards Initiative. Retrieved October 23, 2021, from http://www.corestandards.org/ELALiteracy/standard-10-range-qualitycomplexity/measuring-text-complexity-threefactors/

[17] Common Core State Standards Initiative. (2021). Measuring Text Complexity: Three Factors [Illustration]. http://www.corestandards.org/ELALiteracy/standard-10-range-qualitycomplexity/measuring-text-complexity-threefactors/

[18] Amendum, S. J., Conradi, K., \& Hiebert, E. (2017). Does Text Complexity Matter in the Elementary Grades? A Research Synthesis of Text Difficulty and Elementary Students' Reading Fluency and Comprehension. Educational Psychology Review,
30(1), 121-151. https://doi.org/10.1007/s10648017-9398-2

[19] Creighton, D. C. (1997). Critical Literacy in the Elementary Classroom. Language Arts, 74(6), 438 - 445. http://www.jstor.org/stable/41482896

[20] Jaeger, E. L. (2015). Learning to Construct Meaning From Text: A Case Study of the Relationship Between a Tutor and an English Learner Within a Response to Intervention Setting. Literacy Research and Instruction, 54(4), 285-315. https://doi.org/10.1080/19388071.2015.1062942

[21] Faigley, L., Kress, G., \& van Leeuwen, T. (2002). Multimodal Discourse: The Modes and Media of Contemporary Communication. College Composition and Communication, 54(2), 318. https://doi.org/10.2307/1512155

[22] Ebe, A. E. (2010). Culturally Relevant Texts and Reading Assessment for English Language Learners. Reading Horizons: A Journal of Literacy and Language Arts, 50 (3). Retrieved from https://scholarworks.wmich.edu/reading_horizons/ vol50/iss $3 / 5$

[23] Bunch, G. C., Walqui, A., \& Pearson, P. D. (2014). Complex Text and New Common Standards in the United States: Pedagogical Implications for English Learners. TESOL Quarterly, 48(3), 533559. https://doi.org/10.1002/tesq.175

[24] Drucker, M. (2003). What Reading Teachers Should Know about ESL Learners. The Reading Teacher, 57(1), 22-29. Retrieved September 12, 2021, from http://www.jstor.org/stable/20205312

[25] Bowman-Perrott, L. J., Herrera, S., \& Murry, K. (2009). Reading Difficulties and Grade Retention: What's the Connection for English Language Learners? Reading \& Writing Quarterly, 26(1), 91-107.

https://doi.org/10.1080/10573560903397064

[26] Zehler, A. (1994). Working with English language learners: Strategies for elementary and middle school teachers. NCBE Program Information Guide Series, 19, Washington, DC: National Clearinghouse on Bilingual Education.

[27] Serafini, F. (2010). Reading Multimodal Texts: Perceptual, Structural and Ideological Perspectives. Children's Literature in Education, 41(2), 85-104. https://doi.org/10.1007/s10583-010-9100-5

[28] Meyer, C. F., Halliday, M. A. K., \& Hasan, R. (1987). Language, Context, and Text: Aspects of Language in a Social-Semiotic Perspective. TESOL Quarterly, 21(2), https://doi.org/10.2307/3586740
353. 
[29] Hassett, D. D., \& Curwood, J. S. (2009). Theories and Practices of Multimodal Education: The Instructional Dynamics of Picture Books and Primary Classrooms. The Reading Teacher, 63(4), 270-282. https://doi.org/10.1598/rt.63.4.2

[30] Ajayi, L. (2012). How Teachers Deploy Multimodal Textbooks to Enhance English Language Learning. TESOL Journal, 6, 16-35 